\title{
A Case of a Rare Association Between Right Thyroid Hemiagenesis, Lingual Thyroid, and Papillary Thyroid Cancer
}

\author{
Umal Azmat, ${ }^{1}$ John E Phay, ${ }^{2}$ Theodoros Teknos, ${ }^{2}$ James Bekeny, ${ }^{3}$ and Fadi Nabhan ${ }^{2}$
}

1. Shaukat Khanum Memorial Cancer Hospital and Research Center, Lahore, Pakistan; 2. Division of Endocrinology, Diabetes, and Metabolism, Department of Surgery, Division of Surgical Oncology, Department of Otolaryngology, Ohio State University and Arthur G James Cancer Center, Columbus Ohio, US; 3. Florida Hospital Medical Group, Maitland, Florida, US

\section{Keywords}

Thyroid hemiagenesis, lingual thyroid, thyroid cancer, ectopic thyroid, congenital thyroid abnormality, thyroid nodules

Disclosure: Umal Azmat, John E Phay, Theodoros Teknos, James Bekeny, and Fadi Nabhan have nothing to declare in relation to this article. No funding was received in the publication of this article.

Compliance with Ethics: All procedures were followed in accordance with the responsible committee on human experimentation and with the Helsinki Declaration of 1975 and subsequent revisions, and informed consent was received from the patient involved in this case study.

Authorship: All named authors meet the International Committee of Medical Journal Editors (ICMJE) criteria for authorship of this manuscript, take responsibility for the integrity of the work as a whole, and have given final approval to the version to be published.

open Access: This article is published under the Creative Commons Attribution Noncommercial License, which permits any noncommercial use, distribution, adaptation, and reproduction provided the original author(s) and source are given appropriate credit.

Received: October 19, 2016

Accepted: February 6, 2017

Citation: US Endocrinology, 2017:13(1):35-6

Corresponding Author: Fadi Nabhan, Ohio State University Medical Center, Division of Endocrinology, Diabetes and Metabolism, 575 McCampbell Hall, 1581 Dodd Dr, Columbus, OH 43210, US. E·fadi.nabhan@osumcedu

\section{Case presentation}

A 32-year-old woman presented to our clinic while three months pregnant, with a left-sided neck mass that she had felt about 10 months prior to presentation. She noticed that the mass had grown slightly over that period. She denied symptoms of dysphonia, dyspnea, and dysphagia. A neck ultrasound showed an absent right thyroid lobe and isthmus, along with several left thyroid nodules, with the largest being $4.3 \mathrm{~cm}$ and left lateral malignant appearing adenopathy (largest $3.6 \mathrm{~cm}$ ). Fine-needle aspiration biopsy of the left lateral lymph node was consistent with papillary thyroid carcinoma. The patient had normal thyroid function tests. During her 20th week of pregnancy, the patient underwent a left hemithyroidectomy, left central neck dissection and left lateral neck dissection including levels II-IV. Pathology revealed multifocal papillary thyroid carcinoma with largest focus at $5.2 \mathrm{~cm}$ with extensive vascular invasion and focal extrathyroidal extension. Five out of 12 lymph nodes were malignant (one in central neck and four in left lateral neck). After delivery of a healthy baby, the patient continued to have detectable thyroglobulin (Tg) at $11.5 \mathrm{ng} / \mathrm{ml}$ (Immulite 2000 XPi Thyroglobulin assay, Siemens Inc., Deerfield, IL, which has a functional sensitivity of $0.9 \mathrm{ng} / \mathrm{mL}$ ) with undetectable anti-Tg antibodies with a thyroid stimulating hormone (TSH) level of $0.156 \mathrm{uIU} / \mathrm{ml}$ and ultrasound examination noted a left level II malignant-appearing lymph node. Neck computed tomography (CT) scan confirmed that and that no other suspicious nodes were present, however, it indicated the presence of a lingual thyroid (see Figure 1). The patient did not want to have re-operation or other additional intervention at that time, and she became pregnant again. After delivery and throughout the following year, she continued to have detectable Tg levels at $89.1 \mathrm{ng} / \mathrm{ml}$ with TSH of $9.3 \mathrm{ulU} / \mathrm{ml}$, then $16.4 \mathrm{ng} / \mathrm{ml}$ with TSH of $0.075 \mathrm{ulU} / \mathrm{ml}$ and then $72 \mathrm{ng} / \mathrm{ml}$ with TSH of $86 \mathrm{ulU} / \mathrm{ml}$ (all these $\mathrm{Tg}$ levels were done using the assay mentioned above). A year after she delivered, she agreed to have re-operation that included left lateral neck dissection along with removal of a benign lingual thyroid (see Figure 2). The patient did not agree to receive radioactive iodine treatment. Her most recent thyroglobulin level was done one month after this last surgery and it was at $2.3 \mathrm{ng} / \mathrm{ml}$ (this time the Tg assay was changed to Beckman Access Tg, Beckman Coulter, and was performed at Mayo Clinic Laboratories, Rochester, MN, US, with a functional sensitivity at $0.1 \mathrm{ng} / \mathrm{ml}$ ) with undetectable anti-Tg antibodies with TSH of 0.09 . 
Figure 1: Neck computed tomography scan

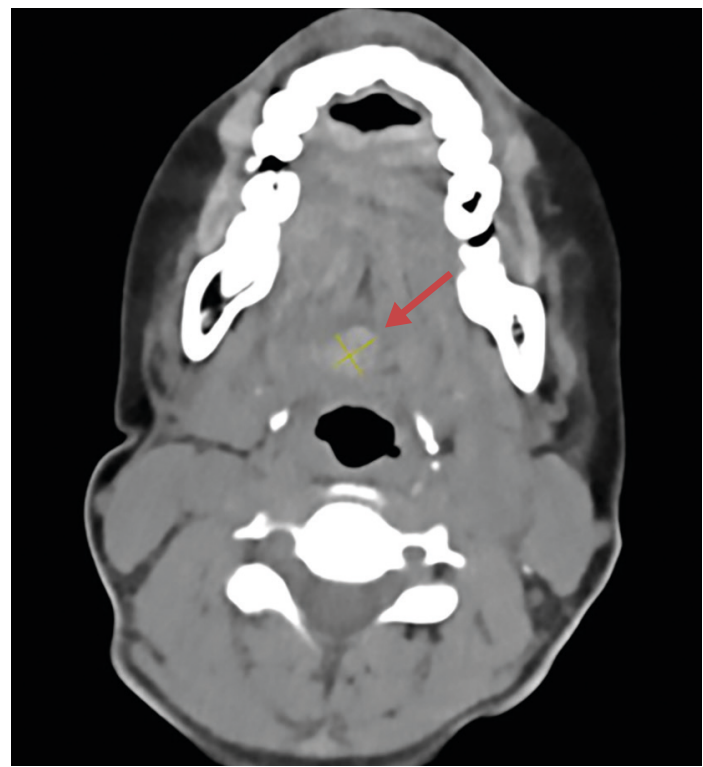

Neck computed tomography scan with the arrow pointing to an ovoid area of increased soft tissue density along the midline posterior tongue centered between the posterior bellies of the genioglossus muscle measuring $1.1 \times 1.1 \mathrm{~cm}$ suspicious for lingual thyroid tissue.

\section{Discussion}

Ectopic thyroid tissue is a rare thyroid developmental abnormality. It is reported to have an incidence of 1 in 5,727 and it is more common in females. ${ }^{1}$ The majority of these patients are asymptomatic; however some may have obstructive symptoms. ${ }^{2,3}$ Hypothyroidism was present in $62 \%$ of patients with lingual thyroid in one series, ${ }^{4}$ while hyperthyroidism is rare. ${ }^{4,5}$ Thyroid cancer arising in ectopic thyroid tissue is extremely rare at less than $1 \%{ }^{6}$

Thyroid hemiagenesis (TH) is another rare developmental abnormality with a prevalence as high as $0.2 \%$ when determined by ultrasound screening. $\mathrm{TH}$ is more common in females and left lobe hemiagenesis comprises more than $80 \%$ of cases. TH is commonly associated with functional and morphological thyroid disorders. ${ }^{8}$

Thyroid cancer is rarely seen in patients with $\mathrm{TH}$. In a review of the literature, associated thyroid cancer was only reported in 3\% of cases of TH. ${ }^{9} \mathrm{TH}$ was also reported to be associated with ectopic thyroid tissue at a similar rate of about 3\%. ${ }^{9}$ The combination of $\mathrm{TH}$ (especially right lobe hemiagenesis), ectopic thyroid tissue and thyroid cancer therefore is
Figure 2: Intraoperative view of the lingual thyroid

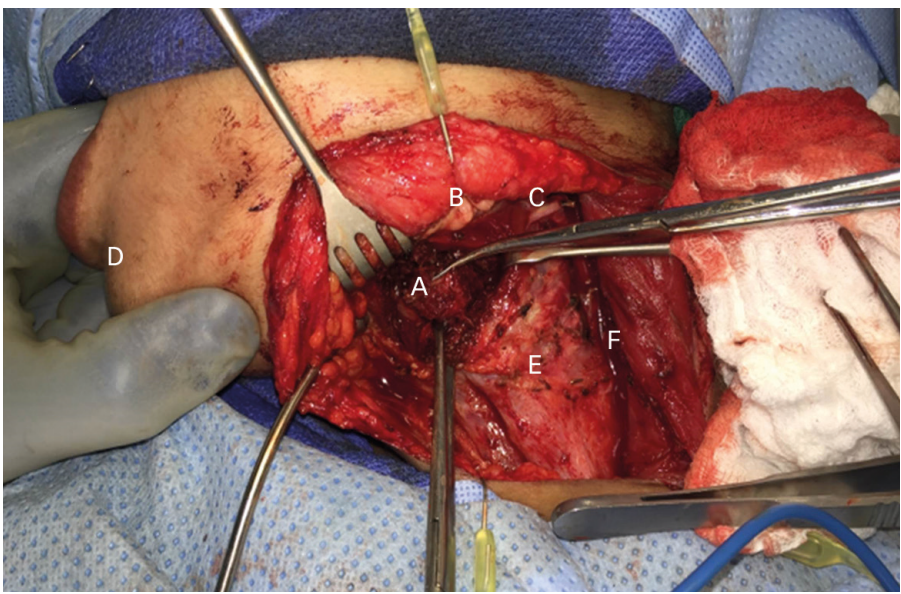

A: the lingual thyroid; B: submandibular gland; C: hypoglossal nerve; D: patient's chin; E: lateral wall of larynx; F: internal jugular vein and carotid artery.

even more uncommon. Huang et al. ${ }^{10}$ described a case of right thyroid hemiagenesis, prelaryngeal ectopic thyroid and thyroid cancer. We report here an additional case of such combination, where the ectopic thyroid tissue was a lingual thyroid.

A key finding in this case is that thyroid cancer was discovered as a metastatic cervical node and the patient was pregnant. Additional imaging before surgery was limited to neck ultrasound, due to pregnancy. The patient was only noted to have lingual thyroid as she continued to have persistent disease after initial surgery and was found to additional cervical nodal disease where further imaging was performed with a CT scan that indicated the presence of lingual thyroid. In the absence of persistent cervical nodal disease, an elevated thyroglobulin in that setting should also alert the physician to check for ectopic thyroid tissue in the setting of $\mathrm{TH}$.

\section{Conclusion}

We report a patient who had the extremely rare association between right $\mathrm{TH}$, thyroid cancer in left lobe and lingual thyroid where lingual thyroid was discovered after the initial surgery for thyroid cancer. While this association is rare, it is very important when evaluating a patient with $\mathrm{TH}$ and thyroid cancer to consider the possibility of the presence of an ectopic thyroid tissue, as this may alter the surgical approach to include the removal of this ectopic thyroid tissue and also may provide an additional source of persistently detectable thyroglobulin after thyroid cancer surgery. $\square$
1. Deladoey t. Ruel I, Giguere $Y$, et al, Is the incidence of congenital hypothyroidism really increasing? A 20-year retrospective population-based study in Quebec, $J$ Clin Endocrinol Metab. 2011;96:2422-9

2. Toso A, Colombani F, Averono G, et al., Lingual thyroid causing dysphagia and dyspnoea. Case reports and review of the literature, Acta Otorhinolaryngol Ital, 2009;29:213-7.

3. Gallo A, Leonetti F, Torri E, et al., Ectopic lingual thyroid as unusual cause of severe dysphagia, Dysphagia, 2001:16:220-3.

4. Carranza Leon BG, Turcu A, Bahn R, et al., Lingual Thyroid: 35-Year Experience at a Tertiary Care Referral Center, Endocr Pract,
2016:22:343-9

5. Abdallah-Matta MP, Dubarry PH, Pessey JJ, et al., Lingual thyroid and hyperthyroidism: a new case and review of the literature, J Endocrinol Invest, 2002;25:264-7.

6. Klubo-Gwiezdzinska J, Manes RP, Chia SH, et al., Clinical review: Ectopic cervical thyroid carcinoma-review of the literature with illustrative case series, I Clin Endocrinol Metab, 2011;96:2684-91.

7. Shabana W, Delange F, Freson $M$, et al., Prevalence of thyroid hemiagenesis: ultrasound screening in normal children, Eur $J$ Pediatr, 2000;159:456-8.
8. Ruchala M, Szczepanek E Szaflarskiw et al Increased risk of thyroid pathology in patients with thyroid hemiagenesis: results of a large cohort case-control study, Eur J Endocrinol 2010;162:153-60.

9. Wu YH, Wein RO, Carter B, et al., Thyroid hemiagenesis: a case series and review of the literature, Am J Otolaryngol 2012;33:299-302.

10. Huang SM, Chen HD, Wen TY, et al., Right thyroid hemiagenesis associated with papillary thyroid cancer and an ectopic prelaryngeal thyroid: a case report, J Formos Med Assoc, 2002;101:368-71. 